\title{
Students and Corporate Social Media: Do College Students Care about Social Media Usernames?
}

\author{
Charles Hooker ${ }^{1}$ \\ ${ }^{1}$ Undergraduate, Department of Sociology, Baylor University, Waco, Texas, United States \\ Correspondence: Charles Hooker, Department of Sociology, Baylor University, Waco, Texas, United States.
}

Received: February 26, 2019

Accepted: June 10, 2019

Available online: June 24, 2019

doi:10.11114/ijsss.v7i4.4092

URL: https://doi.org/10.11114/ijsss.v7i4.4092

\begin{abstract}
Young adults were the first adopters of social media and are still the prominent age group that uses social networking. Businesses have started to capitalize on this by creating a presence on many platforms, including Instagram and Twitter. As college students interact with these businesses on social media, how does the business's social media username affect how college students perceive the business? Prior research from social media marketing articles, like Zarrello (2018), has inferred that the shorter, more attractive usernames are perceived as more professional for companies. A sample of college students were asked to rate the professionalism of a hypothetical company based on various usernames. Respondents preferred usernames containing the company's name with no numbers or symbols, but not necessarily the shortest username.
\end{abstract}

Keywords: usernames, social media, profiles, college students, company, clean, professional

\section{Introduction}

In our digitally-based world, communication is instant. With the click of a button, Lucas can upload an image of his delicious chicken parmesan that he had for dinner that night and, instantly, that photo will be relayed to all the news feeds of those who follow him. Along with the content of a user's posts, comments on other's posts, and a profile picture, users have a social media username associated with their account. Whether it be Instagram, Facebook, Twitter, or any other social media platform, Lucas's distinct and unique username, @ chickenlover123, is tied to the social media account and can be seen by everybody who views the profile.

Social media has changed the way that people interact worldwide. Sociologists have been drawn to social media over the past decade, conducting vast amount of studies to explore the unique forms of interactions among individuals online (Miller et al., 2016). In addition to seeing interactions through posts and replies, friends or acquaintances can also render opinions about an individual by that individual's specific username alone. News articles about companies offering $\$ 20,000$ for certain usernames on Twitter demonstrate that the topic of social media usernames deserves scholarly attention (Sloane, 2013).

The focus of this study is the perception of corporate social media usernames by college students. Young adults were among the earliest social media adopters and remain prominent users of the technology (Pew Research Center, 2017). Because of the ability to reach a wide audience directly via the Internet, small businesses and large corporations alike are utilizing social media as an instrument for interacting with customers and sharing new promotions (Miller et al., 2016; Lyon \& Montgomery, 2013). As college-aged young adults interact with corporate social media accounts, how does the business's social media username affect how college students perceive the business?

\section{Background}

\subsection{Young Adults and Social Media}

Ever since Facebook launched in 2004, social media has taken the Internet by storm. According to Poushter (2017), 76\% of internet users surveyed across 40 countries use social networking websites. Because of the ability to communicate instantly with friends, family, and peers, teenagers and young adults in particular are active users of social media. A staggering $86 \%$ of young adults, between the ages of 19 and 29, are active on at least one social networking site (Pew Research Center, 2017). Teenagers and young adults also spend more time on social platforms than the average person. While the average person spends approximately two hours on social platforms such as YouTube, Facebook, and 
Snapchat every day, Common Sense Media (2015) reports that teenagers spend almost nine hours a day on social media.

According to a recent study conducted by Xu and colleagues (Xu, Yang, Macleod, \& Zhu, 2018, p. 11), "social media has displayed profound influence over human behavior," and they write of the importance of educating college students about digital citizenship and social media competence. Social media can play an integral role in the adjustment to college by helping students gain support from peers (DeAndrea, Ellison, LaRose, Steinfield, \& Fiore, 2012). In addition, through social media like Facebook, the academic learning experience can be increased (Dougherty \& Andercheck, 2014). The authors of all these studies would agree that social media is a large influence in a student's life, hence it is an important topic to study.

\subsection{Social Media Usernames}

A user's content, profile picture or avatar, biography, and username are all elements of an online profile. Specifically, one of the main identifiers of a social media account is the unique username. Usernames can describe the attributes or characteristics of a person, what a person likes, a significant date or event for a person, the actual name of the person or company, or something completely random. As Evans (2014, p. 155), an Internet researcher and author, writes, "a young person expresses his or her identity through a username" and "the use of avatars and usernames in cyberspace also allows young people to explore and experiment with multiple identities." Williams (2003) arrived at the same conclusion in his study of participants in a straightedge internet forum. He concluded that participants displayed their identities through the choice of their username.

People use similar usernames across social media websites and these names "[carry] information that reflect an individual's characteristics and habits" (Wang, Liu, Tan, Shi, \& Guo, 2016). This reflection of "characteristics and habits" relates back to usernames expressing "identities." Just as the username of an individual matters and speaks volumes about the individual's character, companies must choose the right corporate social media username to portray the image they want.

\subsection{Social Media Marketing and Usernames}

As the use of social media by the general public has increased since the early 2000 's, so has the amount of corporate influence. This new form of marketing, oftentimes called social media marketing or social media branding, is very important for companies to interact and share content with customers. These "new technological and social tools" are "redefining interactions between corporations and civil society," playing an integral role in new-age advertising (Lyon \& Montgomery, 2013, p. 747). It is not just large corporations; small businesses use social media to interact with customers and gain popularity (Miller et al., 2016).

Due to the rise of social media marketing, literature ranging from books to online articles has been published to help companies maximize the benefits of social media. In a book authored by co-founders Halligan and Shah (2014, p. 86) of marketing platform HubSpot, there is a section titled "Creating an Effective Online Profile" with a subsection about picking the right username that will gain the most attention online. They give tips like "make your username simple and clean" by staying away from usernames with a "3" as a backwards "E," and "don't include numerals in your username," writing that this makes the account look more "spammy" (p. 86-97). Likewise, blogger Lindsay Kolowich of HubSpot has an entire section in her post about the perfect Instagram profile dedicated to picking a username, "Start by making sure your username is recognizable and easily searchable, like your business name," advises Kolowich (2017). Another blogger from HubSpot, Dan Zarrella (2017), researched the relationship between Twitter usernames and number of followers, and found that accounts with usernames without numbers or underscores have more followers on average than their counterparts. A similar pattern about usernames is seen throughout social media marketing literature. The consensus is that the "cleanliness," or attractiveness, of a corporate username is important for drawing followers to the account.

The importance that social media marketers put on usernames has caused businesses and to quickly grab their company's name as their username on all forms of social media. In a social media marketing industry report published by Stelzner (2016), he records that when a new social media is introduced, $49 \%$ of social media marketers will attempt to make a presence there, with $17 \%$ registering on the new social media just to get their username before others do. Although sometimes a brand can go directly to the social media site to obtain the brand's username, some brands have taken legal action to acquire their trademarked name on certain platforms (Malachowski, 2010). This may be seen as extreme, but Malachowski writes that "controlling a username is becoming as valuable as controlling the brand's or celebrity's native site" (Malachowski, 2010, p. 225). Given this information, it is not surprising that companies will sometimes go to extreme lengths to secure their brand name as their username on social media sites.

Some companies use legal means or directly contact the social media website to obtain usernames. Other companies 
have used alternative routes to acquire usernames. For example, in 2013, JPMorgan Chase reached out to the owner of the Twitter handle @ Chase to try to buy the username for an astonishing \$20,000 (Sloane, 2013). The owner of the handle@Rob, Rob Bertholf, was offered upwards of \$25,000 for his username; he explained, "everybody wants the shorter one, the one that shows they are early adopters, the one they can't get" (Sloane, 2013). The popularity of obtaining these original usernames has even spawned forums like OGUsers.com, which is a site dedicated to the trading of social media accounts and usernames that have advertising potential. The demand for original or brand usernames by companies and individuals is seen in the five-digit price tags that some of these usernames carry, such price tags further show why the username of a company profile is important.

\subsection{Cleanliness}

The theory that this study is testing is the "theory" of cleanliness, which is mentioned by Halligan and Shah (2018) in their book. While there is no official definition, members of the forum OGUsers often write posts of how "clean" a username is, which is a determinant of its value on this third-party market. Elements of cleanliness include shortness, attractiveness, original words, and lack of extra characters such as numbers, letters, and underscores/periods. Just looking at usernames for example, the username @selection would be much cleaner than@selection123 or @_selection_, but not as clean as @ select.

\section{Purpose of the Study}

The purpose of this study is to answer the question: how does a business's social media username affect how college students perceive the business? From the research reviewed above, it is evident that the social media marketing industry has established informal norms for business usernames. Given the amount of literature written from social media marketers on the topic of a professional corporate username, I hypothesize that college students will perceive the professionalism of a company based on how "clean" the username is, described in the section above. That is, shorter usernames without numbers or underscores should be considered most professional by college students. Professionalism, in this sense, is defined as the degree to which a business is competent and skilled in its work, which is being based solely off its username choice.

This study provides clarity in research in an area of literature where studies are lacking. Because social media is so new, many of the studies of it focus broadly on social media. This study, unlike many of the early social media literature, goes in depth into a specific topic, tests it using a survey and analysis, and provides relevant research to the scholarly community for social media and usernames, along with recommendations for future research based on the information provided in this study.

\section{Method}

\subsection{Setting and Audience}

Research was conducted at a private college in the southwest with 16,000 students. Because college-aged students use social media on average for nine hours a day, they are the prime target for a study involving perception of corporate usernames, according to a Common Sense Media (2015) report. Growing up in the early twenty-first century with the rise of social media and mobile phones, these individuals have first-hand experience and knowledge on the topic of social media. Also, their perception of companies on social media has a large impact on the future of social media marketing because they are the age group that is using social networking sites at a higher rate than other age groups.

\subsection{Survey}

Qualtrics was used to conduct an online survey. The survey was administered to students in Introduction to Sociology courses by cooperating professors. Because this is a convenience sample, speculation about a larger population cannot be made, but some insight can be gained about the thought process of college-aged students in general. The survey asked a general question about professionalism: "In general, how important is a social media username to the professional image of a company?" Response options were "not at all important," "slightly important," "moderately important," and "very important."

As a more direct test of the theory, the survey presented a hypothetical company, Exalt Clothing, and asked students to rate the professionalism of the company based solely on different usernames. The usernames were of varying length, contained numbers, underscores, and periods, and a combination of said elements.

Students rated each username on a scale from $0=$ "not professional at all" to $10=$ "very professional." An additional open-ended question asked why the participant believes that one username is more or less professional than another.

I tested if perceptions of username professionalism vary by gender (male and female), ethnicity (recoded into white and non-white), or time spent on social media. The final variable measured the average amount of time per day that a participant spent on social media (less than 1 hour, 1-3 hours, 4-6 hours, 7-9 hours, and more than 9 hours). The time 
segments were decided as such based off the report by Common Sense Media (2015) that claims that teens spend up to 9 hours on social media a day. Full survey questions for all variables are shown in the Appendix A.

\subsection{Survey Statistics}

The online survey was administered in March 2018 and attracted 99 participants. The number of students taking the introductory sociology course at the university totaled 938 , with a response rate of $10.55 \%$. Nearly two-thirds $(62.6 \%)$ of respondents identified as female, $31.3 \%$ identified as male, and $6.1 \%$ did not specify gender. Most of the participating students were white $(66.7 \%)$ with $28.3 \%$ identifying as non-white. Five percent of respondents did not answer the ethnicity question. Over half of participants (53.5\%) recorded that they spend an average of 1-3 hours on social media a day, $25.3 \%$ recorded that they spend an average of $4-6$ hours a day on social media, $14.1 \%$ recorded less than an hour average on social media per day, and only $2.0 \%$ recorded 7-9 hours a day spent on social media. None of the respondents recording using 9+ hours of social media on average per day. Five percent did not report their daily time on social media. For purposes of analysis, time on social media was recoded into two categories of 3 hours or less per day and 4 hours or more per day.

\section{Results}

A majority of students believe that a company's username was either moderately important (40.4\%) or very important (38.4\%) to a company's professional image. Twenty percent $(20.2 \%)$ believe that a company's username is slightly important. Only $1.0 \%$ reported that a company's username is not at all important.

Table 1 shows the average professionalism rating by username for the entire sample. The highest rated username, with an average rating of 9.51 out of 10, was @ ExaltClothing, the name of the hypothetical company with no non-alphabetic characters between or after. The second highest rated username, with an average rating of 8.53 out of 10, was @Exalt_Clothing. The third ranked username was @Exalt.Clothing, being rated on average at 7.73. The fourth ranked username was @Exalt, a shortened name of the hypothetical company Exalt Clothing. The average rating was 6.74. The fifth username, @ExaltClothing, had an average rating of 5.43. The two lowest rated usernames on average were @Exalt_Clothing555 and @ExaltClothing123, both with similarly low ratings of 1.54 and 1.49 respectively.

Table 1. Username Professionalism Average

\begin{tabular}{lc}
\hline Username & Professionalism Score \\
\hline @ExaltClothing & 9.51 \\
@Exalt_Clothing & 8.53 \\
@Exalt.Clothing & 7.73 \\
@Exalt & 6.74 \\
@ExaltClothing__ & 5.43 \\
@Exalt_Clothing555 & 1.54 \\
@ExaltClothing123 & 1.49 \\
\hline
\end{tabular}

For Tables 2 through 4, hypothesis testing using a 2-tailed $t$-test was used to determine whether the mean of the second group significantly differed from the first group. A $t$-test was used due to the small sample size of 99 .

Table 2 shows the average username professionalism rating by gender. The username rankings were in the same order for both males and females, and these rankings by gender were in the same order as the entire sample. There were two usernames that males and females had significantly different ratings. Males rated @Exalt_Clothing and @ExaltClothing_a whole point lower than females did, suggesting that males are less likely than females to believe that an underscore is professional.

Table 2. Username Professionalism Average by Gender

\begin{tabular}{lcc}
\hline Username & Male $(n=31)$ & Female $(n=62)$ \\
\hline @ExaltClothing & 9.29 & 9.63 \\
@Exalt_Clothing & 7.84 & $8.89^{*}$ \\
@Exalt.Clothing & 7.16 & 7.87 \\
@Exalt & 6.94 & 6.48 \\
@ExaltClothing_- & 4.42 & $5.81^{*}$ \\
@Exalt_Clothing555 & 1.42 & 1.39 \\
@ExaltClothing123 & 1.32 & 1.35 \\
\hline
\end{tabular}

Note. A "*" denotes that the means for the username significantly differ by gender, $p<.05$ ( $t$-test, 2 -tailed)

Table 3 shows the average username professionalism rating by ethnicity. Similar to the ratings by gender, the rank order was the same for the two groups and matched the entire sample. Furthermore, whites and non-whites did not differ in their average professionalism score for any of the usernames. 
Table 3. Username Professionalism Average by Ethnicity

\begin{tabular}{lcc}
\hline Username & White $(n=66)$ & Non-white $(n=27)$ \\
\hline @ExaltClothing & 9.53 & 9.48 \\
@Exalt_Clothing & 8.65 & 8.26 \\
@Exalt.Clothing & 7.45 & 8.07 \\
@Exalt & 6.38 & 7.26 \\
@ExaltClothing__ & 5.23 & 5.63 \\
@Exalt_Clothing555 & 1.26 & 1.74 \\
@ExaltClothing123 & 1.23 & 1.63 \\
\hline
\end{tabular}

Note. None of the username means significantly differ by ethnicity ( $t$-test, 2-tailed)

Table 4 shows average username professionalism rating by average time spent on social media per day. The ranking order was the same as the entire sample for those who spent 3 or less hours on social media a day but was different for those who reported using social media for 4+ hours on average per day. The latter ranked @ExaltClothing123 slightly higher than @Exalt_Clothing555. This is important to note, however, because according to social media marketing standards@ExaltClothing123 would be "more professional" since it has fewer characters and no underscore. The username @ExaltClothing was ranked as the most professional by both groups, but respondents who spent 3 or less hours on social media rated this username as significantly more professional than did respondents who spent 4+ hours on social media per day.

Table 4. Username Professionalism Average by Average Hours per Day Spent on Social Media

\begin{tabular}{lcc}
\hline Username & 3 hours or less $(n=67)$ & 4 hours or more $(n=26)$ \\
\hline @ExaltClothing & 9.66 & $9.15^{*}$ \\
@Exalt_Clothing & 8.57 & 8.46 \\
@Exalt.Clothing & 7.76 & 7.31 \\
@Exalt & 6.45 & 7.12 \\
@ExaltClothing_ & 5.54 & 4.85 \\
@Exalt_Clothing555 & 1.37 & 1.46 \\
@ExaltClothing123 & 1.28 & 1.50 \\
\hline
\end{tabular}

Note. A "*" denotes that the means for the username significantly differ by social media use per day, $p<.05$ ( $t$-test, 2-tailed)

Surprisingly, an impressive 86 of the 99 participants (86.9\%) answered the optional written response question about why one username was more or less professional than another username. Although responses varied somewhat, the most common theme was that usernames with no symbols and numbers were the most professional. Participants used words like "official," "clean," and "simple" to refer to usernames like @ExaltClothing and @Exalt. Most participants agreed that a period or underscore should be used when needed by the company. For example, if @ExaltClothing was already taken, one participant stated that @Exalt.Clothing was the most professional because it "is very clean looking and professional by dividing the two words in the name and making it clear for the company name." On the other hand, a few respondents indicated that even periods and underscores looked slightly unprofessional. When referring to the longer usernames with numbers like @ExaltClothing123 and @Exalt_Clothing555, respondents used words like "sloppy," "fake," "tacky," and "distracting." One respondent noted that such usernames looked like "scam accounts."

While the common theme that simpler is more professional was abundant among the responses, some participants noted that usernames can be too simple. Respondent \#6 wrote:

Usernames with numbers are often made because multiple accounts exist with similar names, so it makes the company look less unique. The username should also clearly distinguish the [company's] full name. For example, the username @Exalt was too simple and someone looking to follow [wouldn't] know the type of company.

Respondent \#49 expanded on this idea with an example:

I think when a username contains numbers, it looks very unprofessional. That's mainly what teenagers have in their usernames on Instagram or twitter. For example, you don't see Donald Trump's username on Twitter containing numbers. When a username only has one word or doesn't really describe the company, that isn't very professional either. Above, it shows "@Exalt," but what kind of company is "Exalt?" Is it a jewelry company, clothing company, shoe company?... None of these usernames contain any lower-case letters at the beginning of each word, but if they did, it wouldn't be professional in my opinion.

Responses like these latter two suggest that there is a professional range of usernames that is simple enough to not have numbers and/or underscores and periods, but not too simple as to lose the branding of the company. This would explain why the shorter, more attractive username @Exalt was ranked fourth for average username ratings in the sample, because it was too short. These respondents also clarify the thought process of college students while seeing companies 
on social media. If a student saw @Exalt, they would not know what type of company it was, or even that it was a company at all. Including "clothing" in the username, whether separated from "exalt" by periods/underscores or not, helps define the company's brand and ultimately helps attract customers.

Not all respondents agreed with this argument. There were a couple responses that argued the exact opposite. Respondent \#29 wrote:

Formatting, brand awareness and visibility, brand vision, and memorability all play into [an] account. The username should be definite and memorable, something another brand would not be able to get away with using. For example, Snapchat has@ @ snap on twitter. It's short and sweet, which really gets down to the vision for the service, short and sweet.

He claims that usernames that are professional should be memorable and capture the vision of a company. He would agree that a very short and memorable username like @Exalt would be professional for Exalt Clothing, because it would be memorable and catch the user's eye. He uses Snapchat's Twitter username as an example, @snap, because it is short and sweet, just like photos sent using the Snapchat app.

\section{Discussion}

\subsection{Conclusions Drawn from Results}

Young adults were the first group of people to adopt social media in the early 2000s, and still are the most prominent group using social media. Because of this, their opinion on social media topics is very valuable to social media marketing groups and businesses. Although usernames are not often the focus of social media, they are important, with companies filing lawsuits (Malachowski, 2010) or even offering to buy usernames for five-digit figures (Sloane, 2013). The purpose of this study is to find out if college students care about a business's social media username, and if so, what type of username is perceived by them as being the "most professional."

The findings from a sample of sociology students at one university suggest that students believe just a company's name with no characters between or after is the most professional, with the next two most professional names being the company's name with a period or underscore as a space. The least professional names were the two longest ones with a string of numbers on the end of the company's name. Although I theorized that the shortest username would be considered most professional, this was not this case. The username @Exalt ranked number four of seven. From the written responses, it can be concluded that the reason @Exalt ranked lower is because it is too short and social media users would not be able to tell what type of company "Exalt" is. I theorize that when a company like Exalt Clothing grows large enough, it would be most professional to go by just @Exalt on social media. This is because a large amount of social media users would already have heard of the company. The survey did not go into that much detail about the size or situation of the company. By the wording of the survey, Exalt Clothing may be assumed to be a small business hoping to make a presence on social media.

\subsection{Limitations/Future Research}

While this study did gain insight on what usernames college students perceive as professional and why, it is based on a limited source of data. These data were collected from a convenience sample of college students at one university. Future research on this topic should use larger, preferably probability-based, samples. This study focuses on college students because that age group is the most active on social media, but future studies should examine perceptions of usernames among a wider range of ages. Another suggestion for future research is to expand the survey, with more hypothetical scenarios (i.e. a small business as well as a large corporation, different industries, etc.) and more control variables. One final suggestion for future research is to expand the scope of this study. While this study focuses on usernames specifically, other aspects of a profile such as profile picture, biography, and specific posts can be studied and tested to be professional or not. Research involving the perception of social media usernames by college students helps guide social media marketing groups and businesses to reach the widest audience and to achieve the highest profitability from their social media campaigns.

\section{Acknowledgements}

I thank Dr. Kevin Dougherty of Baylor University for guidance throughout the writing of this paper, helping with administering the survey, and editing.

\section{References}

Common Sense Media. (2015, November 03). The Common Sense Census: Media Use by Tweens and Teens | Common Sense Media. Retrieved from https://www.commonsensemedia.org/research/the-common-sense-census-media-use-by-tweens-and-teens

DeAndrea, D. C., Ellison, N. B., LaRose, R., Steinfield, C., \& Fiore, A. T. (2012). Serious social media: On the use of 
social media for improving students' adjustment to college. The Internet and Higher Education, 15(1), 15-23. https://doi.org/10.1016/j.iheduc.2011.05.009

Dougherty, K. D., \& Andercheck, B. (2014). Using Facebook to Engage Learners in a Large Introductory Course. Teaching Sociology, 42(2), 95-104. https://doi.org/10.1177/0092055X14521022

Evans, S. (2014). The Challenge and Potential of the Digital Age: Young People and the Internet. Transactional Analysis Journal, 44(2), 153-166. https://doi.org/10.1177/0362153714545312

Halligan, B., \& Shah, D. (2014). Inbound Marketing: Get Found using Google, Social Media, and Blogs. City: John Wiley \& Sons, 2014

Kolowich, L. (2017). "The Anatomy of a Perfect Instagram Profile." HubSpot Blog, 28 July 2017, blog.hubspot.com/marketing/optimized-instagram-profile.

Lyon, T. P., \& Montgomery, A. W. (2013). “Tweetjacked: The Impact of Social Media on Corporate Greenwash.” Journal of Business Ethics, 118(4), 747-757. https://doi.org/10.1007/s10551-013-1958-x

Malachowski, D. (2010). "Username Jacking in Social Media: Should Celebrities and Brand Owners Recover from Social Networking Sites When Their Social Media Usernames are Stolen." DePaul Law Review, 60(1), 223-270.

Miller, D., Costa, E., Haynes, N., McDonald, T., Nicolescu, R., Sinanan, J., . . Wang, X. (2016). How the World Changed Social Media. London: UCL Press. Retrieved from http://www.jstor.org/stable/j.ctt1g69z35Pew Research Center. "Social Media Fact Sheet." Pew Research Center: Internet, Science \& Tech, 12 Jan. 2017, www.pewinternet.org/fact-sheet/social-media/

Pew Research Center's Global Attitudes Project, 22 Feb. 2016, www.pewglobal.org/2016/02/22/smartphone-ownership-and-internet-usage-continues-to-climb-in-emerging-econo mies/.

Poushter, J. (2017, March 20). Smartphone Ownership and Internet Usage Continues to Climb in Emerging Economies. Retrieved from https://www.pewresearch.org/global/2016/02/22/smartphone-ownership-and-internet-usage-continues-to-climb-inemerging-economies/

Sloane, G. (2013). “Getting a handle on @Twitter branding.” New York Post, 25 Sept. 2013, nypost.com/2013/09/25/getting-a-handle-on-twitter-branding/.

Stelzner, M. A. (2016). Social Media Marketing Industry Report: How Marketers Are Using Social Media to Grow Their Businesses." Social Media Examiner, 2016.

Wang, Y., Liu, T., Tan, Q., Shi, J., \& Guo, L. (2016). Identifying Users across Different Sites Using Usernames. Procedia Computer Science, 80, 376-385. https://doi.org/10.1016/j.procs.2016.05.336

Williams, J. Patrick. (2013). “The Straightedge Subculture on the Internet: A Case Study of Style-Display Online.” Media International Australia incorporating Culture and Policy, 107(1), 61-74. https://doi.org/10.1177/1329878X0310700108

Xu, S., Yang, H. H., Macleod, J., \& Zhu, S. (2018). Social media competence and digital citizenship among college students. The International Journal of Research into New Media Technologies. https://doi.org/10.1177/1354856517751390

Zarrella, D. (2017). "Picking a Twitter Username? Don't Use Numbers or Underscores.” HubSpot Blog, 28 July 2017, blog.hubspot.com/blog/tabid/6307/bid/4684/picking-a-twitter-username-don-t-use-numbers-or-underscores.aspx. 


\section{Social Media Username Survey}

\section{Appendix A}

Exalt Clothing is a hypothetical company that sells clothing. The owner wants to create a presence on social media for the company. The owner is considering various usernames. On a scale from 0 ("not professional") to 10 ("very professional"), rate the professionalism of Exalt Clothing based solely on the following usernames.

- @Exalt.Clothing

- @ExaltClothing

- @Exalt

- @Exalt_Clothing555

- @ExaltClothing123

- @ExaltClothing

- @Exalt_Clothing

In general, how important is a social media username to the professional image of a company?

- Not at all important

- Slightly important

- Moderately important

- Very important

Why do you believe that one username is or is not more professional than another?

\section{Background}

What is your gender?

- Male

- Female

- Other (please specify)

With which racial group or ethnic group do you most identify?

- White

- Black or African American

- Hispanic or Latino/a

- Asian

- Multiracial

- $\quad$ Other (please specify)

On average, how much time per day do you spend on social media (YouTube, Snapchat, Facebook, etc.)?

- Less than 1 hour

- 1-3 hours

- 4-6 hours

- 7-9 hours

- More than 9 hours

\section{Copyrights}

Copyright for this article is retained by the author(s), with first publication rights granted to the journal.

This is an open-access article distributed under the terms and conditions of the Creative Commons Attribution license which permits unrestricted use, distribution, and reproduction in any medium, provided the original work is properly cited. 